University of Nebraska - Lincoln

DigitalCommons@University of Nebraska - Lincoln

Textile Society of America Symposium

Proceedings

Textile Society of America

2020

\title{
Ways of Life and Works of Weaving and Dyeing in Okinawa: Toward a Possible Solution of Carry on Concern
}

Yuka Matsumoto

Follow this and additional works at: https://digitalcommons.unl.edu/tsaconf

Digitart of the Art and Materials Conservation Commons, Art Practice Commons, Fashion Design

Cemmens, Fiber, Textile, and Weaving Arts Commons, Fine Arts Commons, and the Museum Studies detwerkns

Logo

This Article is brought to you for free and open access by the Textile Society of America at

DigitalCommons@University of Nebraska - Lincoln. It has been accepted for inclusion in Textile Society of America Symposium Proceedings by an authorized administrator of DigitalCommons@University of Nebraska - Lincoln. 


\title{
Ways of Life and Works of Weaving and Dyeing in Okinawa: Toward a Possible Solution of Carry on Concern
}

\author{
Yuka Matsumoto \\ mayuka@edu.u-ryukyu.ac.jp
}

\section{INTRODUCTION}

Weaving and dyeing have been practiced in various parts in Okinawa. They have their own characteristics and thus are often considered as precious cultural resources for each locality. ${ }^{1,2,3}$ Some of them have been even valued as cultural heritage because of relatively long history. More importantly, based on my field experience in Okinawa, all of them, whether historically long or short, have survived or continued with the commitment and efforts of people who wish them to be alive and sustainable., ${ }^{4,5}$ Such efforts are based on their learning from predecessors or by themselves about skills, knowledge, senses, belief, ideas and meaning of different phases of cloth making.

However, it is true that people who are locally engaged in weaving and dyeing have a concern about the sustainable continuity of their activities. In fact the survey which I conducted in 2013-14 in Okinawa shows that people locally engaged in weaving and dyeing tend to decrease in number and are aging. Interestingly, the concern is not always a depressing factor but one of the sources for them to think about and find out a meaning of continuing to involve in local weaving and dyeing.

This way of coping with the concern turns to be a lesson for prospective followers of local weavers and dyers. Through immediate family or media, they come to know about person involved in local cloth making and get interested in the activities. Such interest lets the prospective followers find spontaneously a meaning of work on weaving and dyeing a certain time in their life course. The prospective followers are not literal successor of traditional work but active agents who wish to realize their interest, in other words, strategists in varied and resilient life course.

If it is so, I think it important at this moment to address an issue of how educators play a role to ease the concern of continuing local weaving and dyeing activities. I came to this thinking from the fact that in these years teachers seldom teach about local weaving and dyeing at school in Okinawa. The fact was found from the 2013-14 questionnaire survey on how textile

\footnotetext{
${ }^{1}$ Okinawa-ken Shoukou-roudou-bu Monozukuri-shinko-ka (2014), 43-58.

${ }^{2}$ Higa (1971)

${ }^{3}$ Sano and Matsumoto (2015)

${ }^{4}$ Kerr (1958)

${ }^{5}$ Tanaka and Tanaka (1976)
} 
education was taught at three hundred elementary, junior high and high schools across Okinawa. Then I believed that school teachers need appropriate teaching material and students need a textbook on local weaving and dyeing.

Such informative material, if it be made, would be a potential source for people of any age to get interested in local weaving and dyeing in Okinawa and to even become prospective followers. In order to contribute to alleviating the concern about continuity of local weaving and dyeing, such material should deal with how weavers and dyers "feel" enthusiasm and meanings of their activities and practices in each locality, that is, to describe how local people connect their way of life with weaving and dyeing.

This study is part of an attempt to materialize such descriptions, and at the same time it is to make a practical contribution for one of the principals of Education Guideline issued by Okinawa Prefectural Government; To raise persons who succeed Okinawan specific history, tradition and culture, and who have a pride of Okinawa, working together with families and local residents. Specifically, this study takes two steps. First to find meanings that local people attach to their weaving and dyeing activities, and to analyze how such meanings connect to their life way and how the connection would be useful for sustainable way of life in general. Secondly, to write up a textbook that would be handy for school teachers to use in their classes and for prospective followers to be inspired into various meanings attachable to local textile making, weaving and dyeing practices. The book was eventually published in March, 2020. ${ }^{6}$

\section{METHODS}

This study delineates connections of practicing weaving and dyeing with the way of life at eighteen localities in Okinawa. Each locality is referred by the name of its textile product, that is, Shuri-ori (supplementary weft weaving) and Bingata (stencil) within Naha City; Ryukyu-kasuri (ikat, tie-dye weaving) and Haebaru-hanaori (supplementary weft weaving) in Haebaru Town; Yuntanza-hanawi (supplementary weft weaving), Yuntanza-minsar (ikat sash) in Yomitan Village; Basho-fu (banana fiber (Musa liukiuensis)) in Kijoka, Ogimi Village; Chibana-hanaori (supplementary weft weaving) in Okinawa City; Urasoe-ori (supplementary weft weaving) in Urasoe City; Uji-Zome (sugarcane (Saccharum officinarum) leaf and flower weaving) in Tomigusuku City; Iha-mensar (ikat sash) in Ishikawa, Uruma City; Ryukyu-ai products (dyed by indigo (Strobilanthes cusia) stuff) in Motobu Town; Miyako-jofu (woven with ramie (Boehmeria nivea var.nipononivea) fiber) in Miyako island; Tarama-beni-tsumugi (dyed with safflower (Carthamus tinctorius)) in Tarama Island; Yaeyama-jofu (woven with ramie fiber) in Ishigaki Island; Yaeyama-minsar (ikat sash) in Taketomi Island, Ishigaki

${ }^{6}$ Matsumoto and Sano (2020) 
Island and Iriomote Island; Yonaguni-ori (supplementary weft weaving) in Yonaguni Island; Kumejima-tsumugi (silk ikat) in Kumejima Island; Cloth dyed with indigo (Indigofera suffruticosa) in Kohama Island. In addition to these, Oshima-tsumugi (silk ikat) in Amamioshima Island is included since its cultural features are closely related with Ryukyu culture.

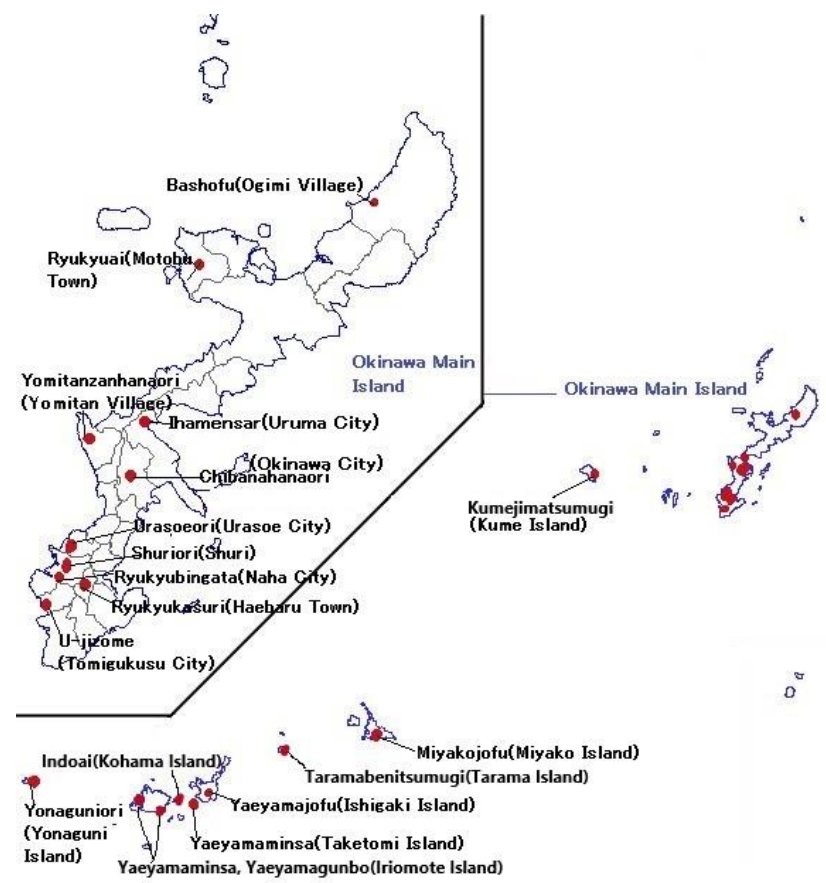

Figure1. Weaving and dyeing map in Okinawa.

After the collection at these localities by using observation and interviewing, the analysis was made with the focus of the following three points. (1) meanings people attach to weaving and dyeing practices in the context of local community life, (2) people's searching and exploring for local culture, and (3) people's seeking for local economic advantage.

\section{RESULTS}

In this section, the meanings which local handicraft people attach to weaving and dyeing practices are described in three groups. The groups are set according to the association with three aspects of people's local lives: (a) connection among people, (b) expression of local culture, and (c) local economic sustenance. Then, we proceed to try to understand more about the relationship of weaving and dyeing practices with local people's individual life history, their family, society, and surrounding nature. 


\section{Meaning of Connecting Local and Remote People}

The connection of people's lives with local life is distinct in five localities: Ryukyu-ai (indigo dye stuff producing) in Izumi, Motobu Town, ${ }^{7,8}$ Miyako-jofu (ramie fiber textile producing) in Miyako Island, ${ }^{9}$ indigo dyeing and weaving in Kohama island, Kumejima -tsumugi (silk ikat weaving and dyeing) in Kumejima Island, ${ }^{10,11}$ and Yonaguni-ori (supplementary weft weaving) in Yonaguni Island. ${ }^{12}$

In Izumi of Motobu Town, manufacturing indigo dye stuff and growing indigo plants are kept by only a few families. Among them, especially one family has maintained to produce dye stuff enough to supply to dyers all over Japan. As the local people began to recognize this family's continuing production as the locality's cultural asset, the family operation has gotten supports from town people.

In the locality of Miyako Island, it is important to raise locally ramie plants as textile material. But keeping the material is not enough to continue to make the textile without keeping spinners to make thread by tying ramie fibers. So, classes of spinning thread were started by the cooperative organization to raise the number of potential spinners. The class is held after supper time for women to attend being free from household chores, and it is held in various sections of the town so that women come to the class by walk. Such arrangement of setting the class came from an idea of the old local customary spinning house with a hope that the classes become a place for knowing and communication each other among the people of each town section.

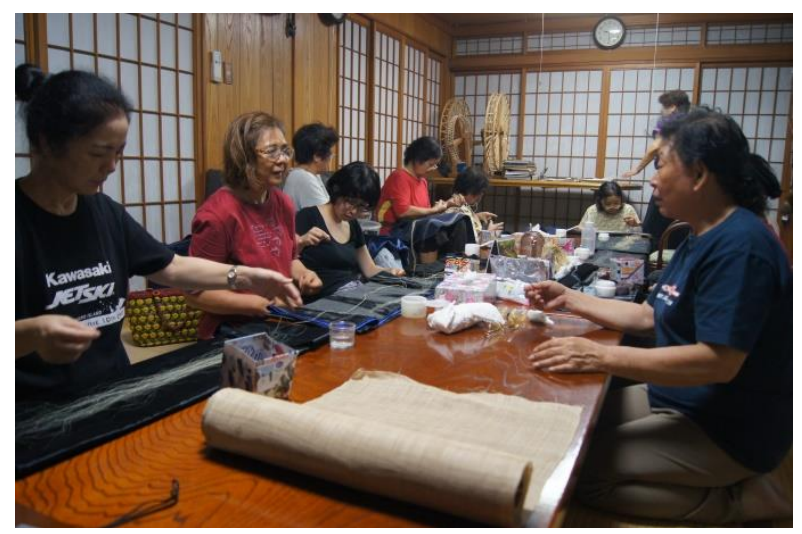

Figure2. A class of spinning thread in Miyakojima City. [Miyako Island, September 2016]

People in Kumejima Island weave and dye in daily lives, and at the time of mud dyeing

\footnotetext{
${ }^{7}$ Kanetsugu, Saichi (1965) 129-131.

${ }^{8}$ Motobu Cho-shi Hensyu Iinkai (1984), 598-616.

${ }^{9}$ Miyako-Jofu Hoji Dantai (2014)

${ }^{10}$ Nakahara (1990)

${ }^{11}$ Yanagi and Yonamine (1994)

${ }^{12}$ Yonaguni-cho Denntou Orimono Kyodo Kumiai (1991), 1-48.
} 
as the most important process of making Kumejima-tsumugi, the system of mutual help is called "Yuimahru" and kept well in local ordinary lives.

In Yonaguni Island, migrants to the island from other prefectures became attracted the local weaving and dyeing. They learned to do such cloth making from island native handicraft makers. Then they work hand in hand with island native people to make locally developed textiles. Eventually they are now creating textiles while keeping traditional methods of weaving and dyeing.

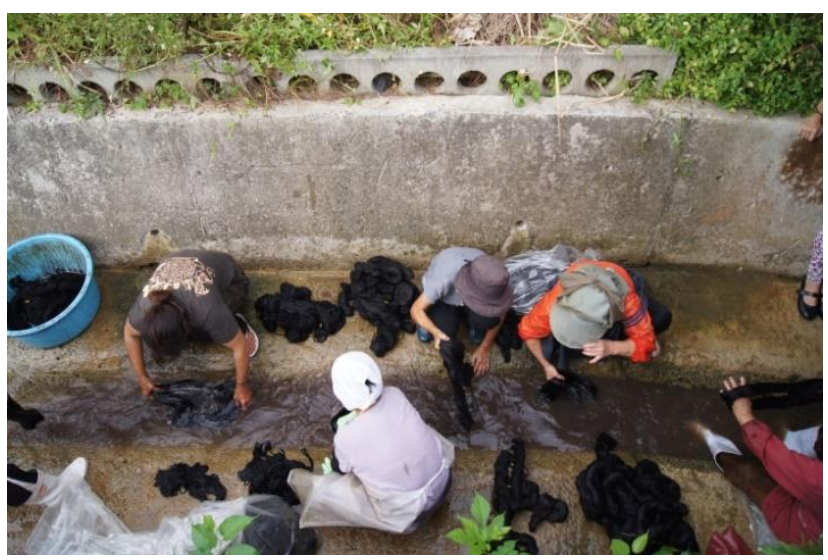

Figure3. Cooperative work of rinsing threads at the end of dirt dyeing for Kumejima-tsumugi. [Maja, Kumejima Island, November 2014]

In Kohama Island, we see more cases that expected in which retired women came back to work on weaving and indigo dyeing. It has been customary practiced grandmothers and great grandmothers make Kimono with cloth they weave and dye for their family members such as adult children and their spouses as well as great children. This kind of Kimono is used for traditional ceremonies and festivals practiced through many generations. Some of the ceremonial festivities are still secretly held only by native islanders. For the elderly women, weaving ad dyeing are great fun and a hope and goal of their lives.

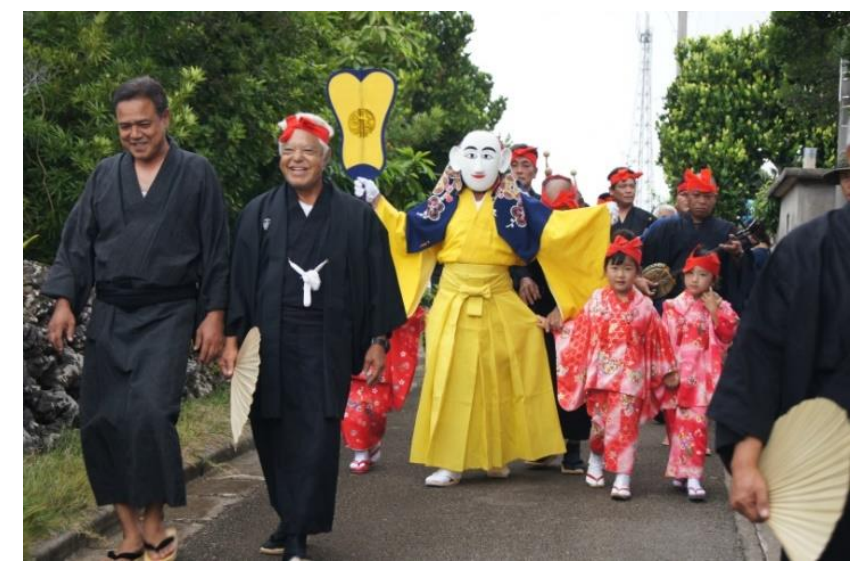

Figure4. The people in Kohama Island wear Kimono made by their family in festivals. [Kohama Island, September 2014] 
In cases of Kumejima Island and Yonaguni Island, the work of weaving and dyeing is suitable job for women who have to manage household affairs, child care and part-time jobs, so that the women are able to play a role of the center bonding family members, relatives and neighbors.

From abovementioned cases, weavers and dyers find consciously or unconsciously meanings of their doing that are closely associated with their daily lives, family cycles and neighborhood relations. They are agents to manage the practice of cloth making in their individual and family life courses and local social life. They actually manage work and life balance, and play a role of connecting immediate and remote people in family and society.

\section{Meaning of Expressing Local Culture}

Among those who are engaged in local cloth production, self-proclaimed artists are barely found in Okinawa while there are surely artists who weave and dye for the sake of their own expressive work. Rather than seeing the textile as site to express individual creative mind, seeing it as a source of various senses, traditionality or historicity is often shared by those who practice local weaving and dyeing. In other words, they see in the process and product of their doing a meaning of involving in and revitalizing their local culture. By having such meaning, they feel spiritual richness.

For instance, people who make Basho-fu interpret the meaning of this textile as "Shizen-fu" (cloth of nature), that is, cloth born from local plants, water, land, wind, sunshine, all elements of nature that has existed over time in the locality going closely with overall regional culture and history of Okinawa. Nature in this wording means not merely physical environment but human touch.

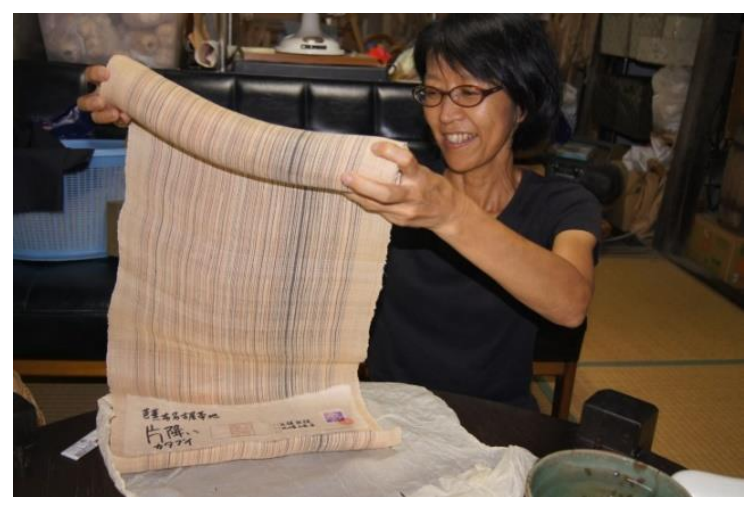

Figure5. Basho-fu made by Ms. Fusae Hirayama. [Kijoka, Ogimi Village, August 2016] 
People who make Chibana-hanaori, ${ }^{13}$ Tarama-beni-tsumugi ${ }^{14}$ and Urasoe-ori study how predecessors made these textiles in the past, especially they like to know how predecessors tried to express their senses and feelings while making textiles in the same environmental setting. People involved now in making the textiles value an idea that the textiles they are making are an expression of locally embedded culture.

People who are engaged in manufacturing Iha-mensar and Yuntanza-hanawi ${ }^{15}$ respectively find a source of pride when they studied that the root of these textiles could be traced to Southeast Asia. So they express certain kind of Southeast Asian features on cloth they make. ${ }^{16}$ Likewise in the case of Bingata ${ }^{17,18}$ and Shuri-ori, ${ }^{19}$ people are consciously aware of them originated from the court culture of Ryukyu Kingdom and they try to keep expressing spiritual wealth on the textiles.

Apart from the locally deep rooted cases, some cases in which there was no locally based weaving and dyeing practices, local administrative offices, such as Tomigusuku City and Urasoe City, initiated to set up an organization of weaving and dyeing hoping to create a new culture to revitalize local community.

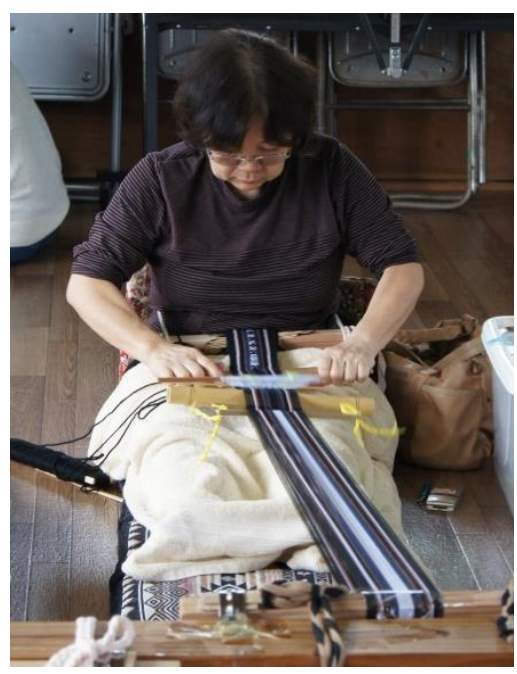

Figure6. Iha-mensar weaving. [Uruma City, February 2014]

13 Chibana-hanaori Jigyo Kyodo Kumiai (2011), 20-22.

14 Tarama-son-shi Hensyu-iinkai (1993), 77-79, 88-89.

15 Sone (1985)

16 Matsumoto and Sano (2015)

17 Kamakura (1981)

18 Yafuso (2010), pp. 113-115.

19 Naha Dennto Orimono Jigyo Kyodo Kumiai (2005) 


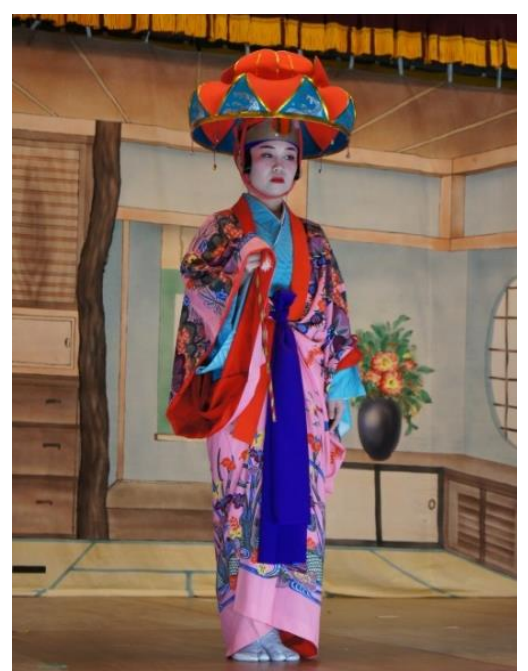

Figure7. Bingata Kimono in Honensai festival. [Izumi, Motobu, September 2015]

From the abovementioned cases, ways of practicing weaving and dyeing vary across Okinawa region in terms of history, locality and environmental setting. However people who involve in doing so are positive agent to study and explore their own local culture. They value what they learn and discover in process and product of their weaving and dyeing, and they are not hesitate to try to express it in their various ways on the process and product of weaving and dyeing.

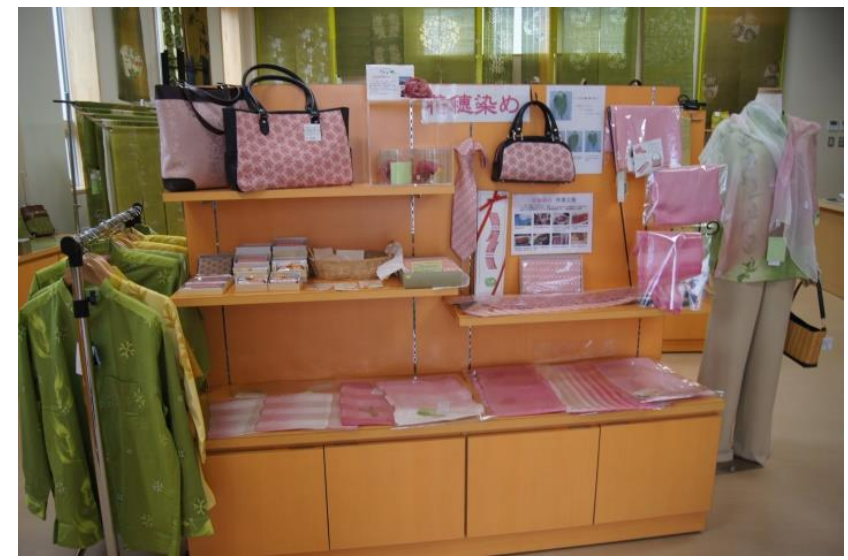

Figure8. Green and pink products by Uji-zome dyeing. [Tomigusuku City, December 2013]

\section{Meaning of Local Economic Sustenance}

Manufacturing textiles have been playing a role not only to keep local culture but also to enrich local economic life. In Okinawa, in some localities, people developed production system and mechanics to meet a demand of larger amount of textiles. The time when such development was started depends on cases, but such developments were obviously first taken place after Meiji period responding to the nationwide modernization and secondly after 
World War Second. Because of larger amount of products, in each below mentioned case, people had to manage cooperative operations and to sustain recruiting and training system while keeping local cultural traits.

In the case of Ryukyu-kasuri ${ }^{20}$ and of Yaeyama-jofu, people make efforts on how to make distinctive motives by rethinking and modifying traditional techniques of weaving and dyeing. From the cases of manufacturing Yaeyama-jofu and making textile goods out of Yaeyama-minsar, ${ }^{21}$ it is impressive to see people continue to make efforts to improve their technique and to update designs by making personal development.

Recent economic orientation becomes linked to tourism. Manufacturing locally based textiles in Okinawa is no exception from this trend. In fact, textiles are made as merchandise products being related to promoting local economy and tourism. Even so, while seeking economic feasibility, people engaged in weaving and dyeing in each locality do not forget to think and rethink about the meaning of handmade, to create new design, to continue renovating techniques. They also seem to enjoy participating in making local based traditional textiles every day.

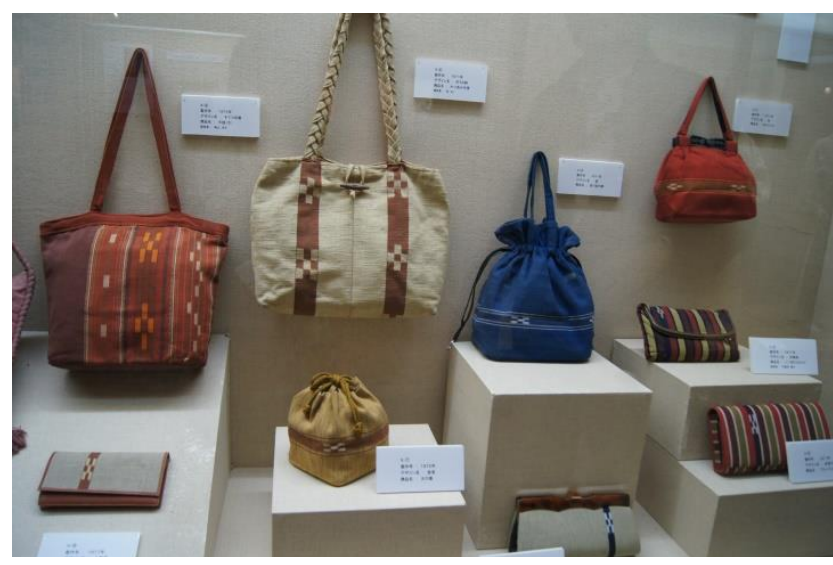

Figure9. The bags made from Yaeyama-minsar. [Ishigaki City, August 2017]

\footnotetext{
${ }^{20}$ Ryukyu Kasuri Jigyo Kyodo Kumiai (2011), 1-2.

${ }^{21}$ Taketomi-cho Orimono Jigyo Kyodo Kumiai (1993) 17-33.
} 


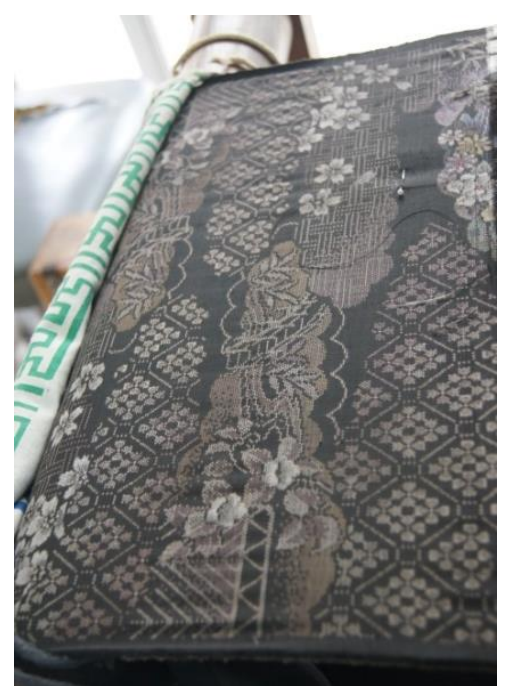

Figure10. Oshima-tsumugi. [Aamamioshima Island, September 2018]

Apart from Okinawa but in its neighborhood islands, Amamioshima Island, People have been manufacturing Oshima-tsumugi (silk ikat weaving). ${ }^{22}$ Its production became on large scale in Meiji Period, but now many workshops are closed due to rapid decrease in Kimono consumption all over Japan. In this situation, some shop owners who wants to survive start to study how workshops in Okinawa survive.

Once local based textile production is linked to larger economic market and also tourism, people tend to concentrate on economic feasibility of textile. However once economy and tourism are down, some people redefine meaning of economic feasibility attached to textiles and shift it to meaning for life, that is, the process and product of weaving and dyeing is a source of fun in work and hope of lives. This shift implies that cloth making could be linked to local economic sustenance.

\section{Relationship with Individual Life History}

Answers to an interview question about the reason of starting to weave and dye suggest that childhood memories are an influential driving force, for instance, a memory of seeing mother, grandmother or women relatives doing so and a memory of pleasant childhood life which contains mother, grandmother or women relatives doing so. Such people who have an experience to weave or to participate in process of cloth making such as spinning do not continue to do so due to schooling or working. However they keep these memories of seeing and experiencing at a corner of mind and the memories loom out later in their life, and then they think about or dwell on what they really like to do. They may eventually begin to participate in weaving and dyeing work.

${ }^{22}$ Honba Oshima-tsumugi Seihan Kyodo Kumiai (1988), 1-3. 
There is a case: those who are not interested in local cloth making tradition and leave their home town to live in larger city, but they begin to recognize fun of the work which their mothers or relatives making local textiles, then come back home to join them doing. Likewise in another case those who leave home to live in larger city realize the significance of home town's culture and then participate in local weaving and dyeing as part of the culture. They get outsider's view while being apart from their home town.

It is interesting to see that people, who have engaged in mass production of such local based textiles as Ryukyu-kasuri and Yaeyama-jofu are now facing with sharp decline, reinterpret what they have done and reorient it for continuation of their local textile toward a practice of challenging to find new ways of making local based textiles even by using self-development and being aware of locally based social responsibility.

Such people rediscover a daily joy in local based textile making. People who experience such joyfulness may proceed to study about and reinterpret local culture, roots of local based textiles, and historical features of Ryukyu Kingdom. Then they try to express creatively what they reinterpret in the process and product of their weaving and dyeing.

\section{Relationship with Family and Society}

People who make local based textiles often work with their family members. There are many cases that they manufacture local textiles as family business. Whether in family business or not, weaving seems to submerge in daily family life. For instance in Kumejima Island, women manage of household chores, child rearing and part time job to find spare time for manufacturing Kumejima-tsumugi. Likewise in Yonaguni Island, women weave and dye by their own pace and seem to manage well to balance work and life. Women of Yonaguni Island also take their own pace in making Yonaguni-ori while taking care of children. Women in Miyako Island tell that sitting at the loom naturally become one of daily customs.

While basing daily activities on family, people who engage in making local based textiles create new linkage between their practice and local community nowadays. For instance, In Miyako Island, people need very fine thread made of ramie fibers for making Miyako-jofu. However people who can make the thread decrease in number. So to keep enough number of thread makers, as we have seen before, concerned people set up classes of thread making. The classes are open to the public, held after supper time, in almost every section of the city. They are also meant to play a role as a free gathering place for community people like old time "spinning house" so that more ordinary people are able to come to meet other people and to know about Miyako-jofu and the importance of keeping enough people who make threads. 
Regarding new gathering opportunity to know about local textile, people of Kohama Island have long held a community textile exhibition held by women's association once a year in community hall where island inhabitants are able to show their own textile products. Usually elderly women participate in this and exchange ideas and talk about the exhibited products.

In Kumejima Island, veterans of making local based textile play a role as a tutor to help local community members learn how to weave and dye. This role also functions as another role of community care because gathering opportunity brings more or less intimate ties among participants.

Extending social role of dyeing practice beyond community is seen in the case of Izumi Section of Motobu Town. As we have seen early, one family operation of making indigo dye staff has survived so far due to local community people's understanding and cooperation as well as supports from prefectural and national government, namely Agency of Cultural Affairs.

In the case of Ishigaki Island, a private company which both manufactures and merchandizes textiles and textile goods recently begins to hold a local textile exhibition as part of the company's social responsibility to the local community. This new activity is not for the company's profit but for contributing to the promotion of locally made textiles and textile goods in general.

Because of nationwide modernization and recent tourism-oriented trend, people who make local textiles have had more direct ways of relating with society. Responding to rising mass consumptive demand, manufacturing cooperatives were organized across Okinawa region. Small-scale supply chains were made with division of labor in the process of manufacturing, namely planting, thread making, weaving, dyeing and selling. The divisions depended on each other, so that the relationship among division people was carefully managed. The cooperatives were incessantly involved in innovating technology, creating new design and training prospective weavers and dyers. Recent tourism drives township and municipal governmental offices to take such cooperatives' role in various localities. They try to initiate to reconnect the locality with larger society, even global world. There is a case which the local government creates new textiles, and the people join to producing such textiles and it becomes locality's original.

\section{Relationship with Surrounding Nature}

There are new changes in the way in which people relate their making local-based textiles with the locality where they live or work. With the background of recent global 
environmental consciousness, they recognize the connection between what they make and their surrounding nature. In fact, places of local-based textiles are often located in communities rich in natural resources of stuff for weaving and dyeing such as Iriomote island of Okinawa's western area and Kunigami of northern Okinawa Main Island. People in such localities are conscious in taking from nature the amount of things only necessary for making textiles. They consider these things are the gift of nature and try to show their sense of nature in their products like Basho-fu and Minsar Sash.

There are some local-based textiles for which people need clean sea water in the process of textile making. They wash the product in the sea. Still doing so in traditional way, people in Iriomote Island call the design they make as "sustainable design", which implies that they are crafting without burdening surrounding environment.

\section{CONCLUSION}

I conclude this paper by pointing the following three understandings to alleviate a concern of current condition in which local-based textile makings stand and to achieve a goal to make the local-based textile makings sustainable.

First, to understand how local-based textiles help the people in Okinawa. Weaving and dyeing can become fun and a hope of life, that is, 'IKIGAI' for those who engage in textile making. They can lead local people to be independent while making them connecting with their family, local community and even larger society.

Secondly, to understand the variety of meanings attached to weaving and dyeing. They are not special for the elderly lives in more or less isolated islands but for multi generations, retirees, middle-ages, young people who may become prospective weavers and dyers in a certain stage of their life courses.

Thirdly, to understand that local-based textile making can be connected to sustainable lives in each locality. Local-based textile makings can be connected with people's lives through expressing local old and new culture, senses of relating with their families, societies and natural environment.

\section{ACKNOWLEDGEMENTS}

This study was supported by JSPS KAKENHI Grant Number JP15K04505 from 2015 to 2018. I would like to thank Dr. Toshiyuki Sano for his critical comments and suggestions to early versions of this paper. 


\section{BIBLIOGRAPHY}

Chibana-hanaori Jigyo Kyodo Kumiai. (2011) Dentoteki Kougeihin Shitei no Moushide-syo (Application Form to Designate as Traditional Craft Goods). Booklet issued by author, cooperative union, 2011.

Higa, Shyncho. (1971) “Okinawa no Rekishi (History of Okinawa)” in Higa Shyuncho Zensyu dai 1 Kan, rekishi-hen 1 (Complete Works of Higa Shuncho). Volume 1, History Part, Okinawa Times Publishers, 1971.

Honba Oshima-tsumugi Seihan Kyodo Kumiai. Honba Amamioshima-Tsumugi Tekisuto (Textbook of Authentic Amamioshima- Tsumugi). Booklet issued by author, cooperative union, 1988.

Kamakura, Yoshitaro. (1981) Ryukyu Bingata. Nihon no Sensyoku 10 (Japan's Weaving and Dyeing, No.10). Tairyu-sha., 1981, 30-43.

Kanetsugu, Saichi. Izumi-shi (Historiography of Izumi). Ryukyu Shiryo Kenkyu-kai, 1965.

Kerr, George H. Okinawa; The History of an Island People. Charles E. Tuttle Company, 1958.

Matsumoto, Yuka and Sano Toshiyuki. Indonesia, Aceh no Hukusyoku-kougei ni Miru Tsunami-go no Henka (Tradition and Post-Tsunami Changes in Clothing and Crafts of Aceh, Indonesia). Minzoku Geijyutu (Ethno Arts), Volume 31, 2015, 100-107.

Matsumoto, Yuka and Sano Toshiyuki. Okinawa no Some-Ori to Hitobito no Kurashi: Kazoku to Chiiki-Bunka, Keizai to Tuhrizumu kara Kangaeru (Weaving and Dyeing in Okinawa and People's Lives: In Connection with Family and Local Culture, Economy and Tourisms). Ryukyu Shimposya, 2020.

Miyako-Jofu Hoji Dantai. Miyako-jofu, Sono Tewaza. Kaitei-ban (Miyako-jofu, its Hand Skillful Works. revised edition). Booklet issued by author, sustaining organization, 2014. Motobu Cho-shi Hensyu Iinkai. Motobu Cho-shi, Shiryo-hen 2 (History of Motobu Town. Sources Part 2). Motobu-cho Yakuba (Motobu Town Office), 1984.

Naha Dennto Orimono Jigyo Kyodo Kumiai. Shuri-ori no Rekishi to Giho (History and Teciniques of Shuri-Ori Textile). Booklet issued by author, cooperative union, 2005.

Nakahara, Yoshihide. Daiichiwa; Kumejima no Iseikatsu, Daishichiwa; Kumejima-tsumugi no Ayumi (Chapter 1; Clothing Life of Kumejima, Chapter 7; The Progress of Kumejima-tsumugi). in Uezu Hitoshi (ed.) Kume-jima no Rekishi to Minnzoku. (History and Folklore of Kume Island), Daiichi-Shobo Publishing, 1990, 1-32, 147-185.

Okinawa-ken Shoukou-roudou-bu Monozukuri-shinko-ka. Kohgei Sangyo Shinko Sesaku no Gaiyou 2014 (Outline of Politics to Promote Craft Industry 2014). Okinawa Prefectural Office, 2014.

Ryukyu Kasuri Jigyo Kyodo Kumiai. Haebaru-cho no Ori, Ryukyu-Kasuri, Haebaru Hana-Ori (Woven Textile of Haebaru Town, Ryukyu-Kasuri (ikat) and Haebaru Flower Textile with supplementary weft). Booklet issued by author, cooperative union, 2011. 
Sano, Toshiyuki and Matsumoto Yuka. (2015) "Changes in the Way of Traditional Cloth Makings and the Weaver's Contribution in the Ryukyus," Textile Society of America 14th Biennial Symposium Proceedings. Textile Society of America, University of Nebraska Digital Commons, Lincoln, 2015, 1-10.

Sone, Shinichi. (1985) "Yuntanza no Orimono no Rekisi (History of Yuntanza's Textiles)," in Yuntanza Hanawi no Rekishi to Gihou (History and Techniques of Yuntanza Hanawi). Yuntanza Manufacturing Cooperative Union, 1985, 1-19.

Taketomi-cho Orimono Jigyo Kyodo Kumiai. Yaeyama-minsar, Minsar no Rekishi to Ori, Some (Yaeyama-minsar: History and Weaving/Dyeing of Minsar). Booklet issued by author, cooperative union, 1993.

Tanaka, Toshio and Tanaka Reiko. Okinawa Orimono no Kenkyu (A Study of Textiles of Okinawa). Shiko-sha, 1976.

Tarama-son-shi Hensyu-iinkai. Tarama-son-shi, Dai 4 Kan, Shiryo-hen 3 (Minzoku). (History of Tarama Village, Volume 4, Source 3). Tarama Village Office, 1993.

Yafuso, Sachiko. (2010) Ryukyu Bingata (Ryukyu's Bingata Style). Issen, 2010.

Yanagi, Yoshikuni and Yonamine Ichiko. (1994) "Kume-jima no Sensyok Shiryo Gaikan" ("Overview of Textile Material of Kumejima"), in Okinawa Prefectural Museum (ed.) Kumejima Sogo Chousa Houkokusyo (Report of Comprehensive Research on Kumejima Island), 1994, 205-215.

Yonaguni-cho Denntou Orimono Kyodo Kumiai. (1991) Yonaguni Ori (Yonaguni-ori Textile). Booklet issued by author, co-operative union, 1991. 